\title{
Monte Carlo Solution Convergence Analysis via COMET in a Stylized Integral Inherently Safe LWR Benchmark Problem
}

\author{
Dingkang Zhang and Farzad Rahnema \\ Georgia Institute of Technology \\ 770 State Street NW, Atlanta, GA 30332-0745 \\ dingkang.zhang@gatech.edu, farzad@gatech.edu ${ }^{1}$
}

\begin{abstract}
In this paper, the coarse mesh radiation transport (COMET) method is used to study the convergence of the Monte Carlo solution in a stylized benchmark problem based on the beginning of the equilibrium cycle of the Integral Inherently Safe Light Water Reactor concept ( ${ }^{2} \mathrm{~S}-\mathrm{LWR}$ ) with silicide $\mathrm{U}_{3} \mathrm{Si}_{2}$ fuel. The benchmark problem is comprised of 121 fuel assemblies with radial, top and bottom reflectors. COMET consists of a stochastic local solver (response function generator) for generating a library of incident flux response expansion coefficients for the unique coarse meshes (e.g., all fuel assembly types and reflector/non-fuel blocks) and a deterministic iterative solver for whole-core calculations using this response library. The Monte Carlo method is regarded as the gold standard for benchmarking other numerical transport methods. However, for eigenvalue problems, Monte Carlo results require careful analysis to ensure the convergence of the fission source distribution. It is known that this issue can be of concern, particularly for large eigenvalue problems typical of realistic (i.e., operating) reactors. This became evident when the radially-integrated axial fission density distributions predicted by 50 independent MCNP runs in the $I^{2}$ S-LWR benchmark problem were compared to each other and were found to be significantly different, with the difference ranging from $-9 \%$ to $+9 \%$. However, the average of the fission density distributions from these 50 runs agreed very well with that predict by COMET, with a relative difference varying from $-0.18 \%$ to $0.13 \%$, being within one standard deviation of the average. This agreement confirms that the averaged Monte Carlo solution is converged.
\end{abstract}

Key Words: Coarse Mesh Neutron Transport, $\mathrm{I}^{2} \mathrm{~S}$ Reactor, Reactor Analysis

\section{Introduction}

The Integral Inherently Safe Light Water Reactor $\left(I^{2} S-L W R\right)$ is a new reactor concept which aims to improve safety and economics of future nuclear plants through significant innovations such as safety approach and novel design of nuclear fuel. Recently a stylized benchmark problem (Hon et al., 2016) of the $\mathrm{I}^{2} \mathrm{~S}-\mathrm{LWR}$ core was developed for the purpose of testing neutronics transport codes and methods.

Generally, the Monte Carlo method is used for numerical benchmarking of deterministic methods since it is regarded as the gold standard because of generalized geometry capability and

\footnotetext{
${ }^{1}$ Corresponding author and email address
} 
its high accuracy. This method solves the problem by simulating a large number of particle histories in the system. Then, the physical quantities of interest are computed (tallied) from the average behavior of the simulated particles. In eigenvalue problems, the fission source distribution is unknown and as a result must be converged upon before the tallying of parameters of interest such as the eigenvalue and pin fission density distribution are performed. Therefore, these tallies (problem solution) require a careful analysis/inspection to ensure the convergence of the fission source distribution. The Shannon entropy is widely used as an indicator of convergence. However, the entropy indicator sometimes may not be reliable because of the possibility of the false positive diagnostics (Ueki and Brown, 2005). It is known that this issue can be of concern particularly for large eigenvalue problems typical of realistic (i.e., operating) reactors in which the dominance ratio is very close to 1 . In this paper, the $\mathrm{I}^{2} \mathrm{~S}$ benchmark problem is used to study the fission source convergence of the Monte Carlo code MCNP5 (X-5 Monte Carlo Team, 2005). The finding of this study is supported by the coarse mesh transport method (COMET) (Mosher and Rahnema, 2006; Zhang and Rahnema, 2012a). A brief description of this method is found in section 4 for the reader's convenience.

The remainder of the paper is organized as follows. The benchmark problem is summarized in section 3. The MCNP5 and COMET solutions as well as their comparison are presented in section 4. Conclusions and discussion are found in section 5.

\section{COMET method}

The COMET code is a hybrid stochastic/deterministic neutronics method for core criticality analysis. It provides transport solutions to highly heterogeneous reactor cores in Cartesian, hexagonal and cylindrical geometries. Extensive benchmark calculations (Zhang and Rahnema, 2012a, 2012b and 2012c; Rahnema, Zhang and Connolly, 2014; Ulmer, Rahnema and Connolly, 2016) in PWRs, BWRs, CANDUs, gas cooled thermal reactor cores (HTTRs and PBRs), and faster reactor (e.g., ABR) configurations have demonstrated its high accuracy and computational efficiency. The full description of the COMET method can be found in Mosher and Rahnema (2006) and Zhang and Rahnema (2012a). For the sake of the reader, the COMET method is briefly presented in this section.

The first step in the method is to decompose the spatial domain $\boldsymbol{V}$ of the global problem of interest into a number of non-overlapping regions $\left\{\boldsymbol{V}_{\boldsymbol{i}}, \boldsymbol{i}=\mathbf{1}, \mathbf{2}, \ldots, \boldsymbol{N}\right\}$ which are referred to coarse meshes in the remainder of the paper. Assuming that the outgoing/incoming flux on coarse mesh interfaces can be sufficiently represented by a linear combination of a finite number of orthogonal expansion functions $\Gamma_{m}(\vec{r}, \widehat{\Omega}, E)$, the outgoing partial current moment from a coarse mesh can be computed as a superposition of all incoming flux moments entering from contiguous coarse meshes, taking into account the possibility of contribution of the incident particles and their progenies.

$$
J_{i s}^{+, m}=\sum_{s^{\prime}, m^{\prime}} R_{i s^{\prime} s}^{m^{\prime} m}(k) J_{i s^{\prime}}^{-, m^{\prime}},
$$

where $J_{i s}^{ \pm, m}$ represents the $m^{\text {th }}$ moment of the outgoing/incoming current crossing surface $s$ of coarse mesh $i, k$ denotes the core eigenvalue, and $R_{i s^{\prime} s}^{m^{\prime} m}$ represents the surface-to-surface response coefficient for coarse mesh $i$. 
The numerical steps in COMET consists of the following: local calculations to obtain response coefficients for each unique coarse mesh and global calculations to converge on the outgoing/incoming partial current moments and the core eigenvalue.

In the local calculations, the Monte Carlo method is used to solve a set of fixed-source problems to obtain the response functions for each unique coarse mesh with the fission neutrons scaled by the factor $1 / k$.

$$
\mathbf{H} R_{i s}^{m}(\vec{r}, \widehat{\Omega}, E)=\frac{1}{k} \mathbf{F} R_{i s}^{m}(\vec{r}, \widehat{\Omega}, E) \quad \vec{r} \in V_{i},
$$

with the boundary condition:

$$
R_{i s}^{m}(\vec{r}, \widehat{\Omega}, E)=\left\{\begin{array}{c}
\Gamma_{m}(\vec{r}, \widehat{\Omega}, E), \quad \vec{r} \in \partial V_{i s} \text { and } \hat{n}_{i}^{+} \cdot \widehat{\Omega}<0 \\
0, \vec{r} \in \partial V_{i}-\partial V_{i s} \text { and } \hat{n}_{i}^{+} \cdot \widehat{\Omega}<0
\end{array}\right.
$$

In the above equations, the $R_{i s}^{m}(\vec{r}, \widehat{\Omega}, E)$ is the surface-to-volume response function, $V_{i}$ represents the spatial domain of coarse mesh $i$ with boundary $\partial V_{i}, \partial V_{i s}$ represents surface $s, \hat{n}_{i}^{+}$ denotes the outward normal on $\partial V_{i}$, and $\mathbf{H}$ and $\mathbf{F}$ stand for the transport and fission operators. It is clear from Equations (2) and (3) that the response function $R_{i s}^{m}(\vec{r}, \widehat{\Omega}, E)$ represents the flux distribution in coarse mesh $i$ due to a unit incident flux $\Gamma_{m}(\vec{r}, \widehat{\Omega}, E)$ imposed on surface $s$. The Monte Carlo method is chosen to generate response functions so that the geometric details and material heterogeneities of each coarse mesh can be fully modeled. It should be noted that response functions need to be generated (i.e., pre-computed) for only the coarse meshes that are unique in geometry and composition. Furthermore, the pre-computation of the response functions is generally very efficient since each calculation is to solve a small local fixed-source problem with vacuum boundary condition. In this process, the surface-to-surface response coefficients $R_{i s^{\prime} s}^{m^{\prime} m}$ and the response pin fission densities $R F D_{i s}^{m j}$ can be tallied simultaneously. Those response coefficients are then compiled into a library for the global core calculations.

In global calculations, a two-level iterative deterministic solver (Zhang and Rahnema, 2012a) is used to obtain the whole-core solution. At the inner iteration level, Equation (1) is repeatedly utilized to converge on the outgoing/incoming partial current moments crossing coarse mesh boundaries. At the outer iteration level, the global particle balance equation is used to converge on the core eigenvalue. Once outgoing/incoming partial current moments and the core eigenvalue are converged, the flux and pin fission density distributions in each coarse mesh can be simply computed as a superposition of all contributions resulting from incident flux moments entering from the contiguous coarse meshes via the pre-computed response functions.

\section{I'S-LWR Benchmark Problem}

The simplified I'S-LWR beginning of cycle core benchmark problem is fully described in the companion paper (Hon et al., 2016). For the sake of completeness, it is briefly described in this section. The $I^{2} S$ reactor has geometry based on a Westinghouse 2-loop pressurized water reactor design while its power is similar to that of current large commercial PWRs ( $1000 \mathrm{MWe})$. The core consists of 121 assemblies. Its radial configuration of the quarter core is shown in Fig. 1 in 
which the top-left assembly is the center of the rector. The core is surrounded by a radial reflector (blank regions in Fig. 1) which is a mixture of $70 \mathrm{wt. \%}$ standard steel and $30 \mathrm{wt} \%$ water.

\begin{tabular}{|c|c|c|c|c|c|c|}
\hline $\begin{array}{c}4.65 \% \mathrm{U}- \\
235\end{array}$ & $\begin{array}{c}4.45 \% \mathrm{U}- \\
235\end{array}$ & $\begin{array}{c}4.65 \% \mathrm{U}- \\
235\end{array}$ & $\begin{array}{c}4.45 \% \mathrm{U}- \\
235\end{array}$ & $\begin{array}{c}4.65 \% \mathrm{U}- \\
235\end{array}$ & $\begin{array}{c}4.65 \% \mathrm{U}- \\
235\end{array}$ & $\begin{array}{c}4.65 \% \mathrm{U}- \\
235\end{array}$ \\
\hline $84 \mathrm{IFBA}$ & 84 IFBA & 100 IFBA & 84 IFBA & 84 IFBA & 84 IFBA & 84 IFBA \\
\hline $2 \times$ burned & Ixburned & 0xburned & $2 \times$ burned & Ixburned & 0xburned & $2 \times$ burned \\
\hline $\begin{array}{c}4.45 \% \mathrm{U}- \\
235\end{array}$ & $\begin{array}{c}4.65 \% \mathrm{U}- \\
235\end{array}$ & $\begin{array}{c}4.45 \% \mathrm{U}- \\
235\end{array}$ & $\begin{array}{c}4.65 \% \mathrm{U}- \\
235\end{array}$ & $\begin{array}{c}4.45 \% \mathrm{U}- \\
235\end{array}$ & $\begin{array}{c}4.65 \% \mathrm{U}- \\
235\end{array}$ & $\begin{array}{c}4.45 \% \mathrm{U}- \\
235\end{array}$ \\
\hline 84 IFBA & 100 IFBA & I 56 IFBA & 84 IFBA & I 56 IFBA & 84 IFBA & 84 IFBA \\
\hline Ixburned & $2 \times$ burned & Ixburned & Ixburned & 0xburned & 0xburned & $2 \times$ burned \\
\hline $\begin{array}{c}4.65 \% \mathrm{U}- \\
235\end{array}$ & $\begin{array}{c}4.45 \% \text { U- } \\
235\end{array}$ & $\begin{array}{c}4.45 \% \mathrm{U}- \\
235\end{array}$ & $\begin{array}{c}4.45 \% \mathrm{U}- \\
235\end{array}$ & $\begin{array}{c}4.45 \% \mathrm{U}- \\
235\end{array}$ & $\begin{array}{c}4.45 \% \mathrm{U}- \\
235\end{array}$ & \\
\hline 100 IFBA & I 56 IFBA & 84 IFBA & 84 IFBA & 84 IFBA & I 56 IFBA & \\
\hline oxburned & Ixburned & Ixburned & Ixburned & 0xburned & $2 \times$ burned & \\
\hline $\begin{array}{c}4.45 \% \mathrm{U}- \\
235\end{array}$ & $\begin{array}{c}4.65 \% \mathrm{U}- \\
235\end{array}$ & $\begin{array}{c}4.45 \% \mathrm{U}- \\
235\end{array}$ & $\begin{array}{c}4.65 \% \mathrm{U}- \\
235\end{array}$ & $\begin{array}{c}4.45 \% \mathrm{U}- \\
235\end{array}$ & $\begin{array}{c}4.65 \% U- \\
235\end{array}$ & \\
\hline 84 IFBA & 84 IFBA & 84 IFBA & 100 IFBA & 84 IFBA & 84 IFBA & \\
\hline $2 \times$ burned & Ixburned & Ixburned & Ixburned & 0xburned & $2 \times$ burned & \\
\hline $\begin{array}{c}4.65 \% \mathrm{U}- \\
235\end{array}$ & $\begin{array}{c}4.45 \% \text { U- } \\
235\end{array}$ & $\begin{array}{c}4.45 \% \mathrm{U}- \\
235\end{array}$ & $\begin{array}{c}4.45 \% \mathrm{U}- \\
235\end{array}$ & $\begin{array}{c}4.45 \% \mathrm{U}- \\
235\end{array}$ & & \\
\hline 84 IFBA & I 56 IFBA & $84 \mathrm{IFBA}$ & 84 IFBA & 84 IFBA & & \\
\hline Ixburned & 0xburned & 0xburned & Oxburned & $2 \times$ burned & & \\
\hline $\begin{array}{c}4.65 \% \mathrm{U}- \\
235\end{array}$ & $\begin{array}{c}4.65 \% \mathrm{U}- \\
235\end{array}$ & $\begin{array}{c}4.45 \% \mathrm{U}- \\
235\end{array}$ & $\begin{array}{c}4.65 \% \mathrm{U}- \\
235\end{array}$ & & & \\
\hline 84 IFBA & 84 IFBA & I 56 IFBA & 84 IFBA & & & \\
\hline 0xburned & 0xburned & $2 \times$ burned & $2 \times$ burned & & & \\
\hline $\begin{array}{c}4.65 \% \mathrm{U}- \\
235\end{array}$ & $\begin{array}{c}4.45 \% U- \\
235\end{array}$ & & & & & \\
\hline 84 IFBA & 84 IFBA & & & & & \\
\hline $2 \times$ burned & $2 \times$ burned & & & & & \\
\hline
\end{tabular}

Fig. 1. Radial quarter-core representation of the $\mathrm{I}^{2} \mathrm{~S}$ benchmark problem (Hon et al., 2016). Note: The top-left assembly is in the center of the reactor core.

As shown in Fig. 2, the axial configuration of the core consists of 21 regions: a bottom reflector, a bottom blanket, a bottom cutback region, 5 bottom fuel regions, 5 middle fuel regions, 5 top fuel regions, a cutback region, a top blanket, and a top reflector. The height of each axial region is shown in Table 1. 


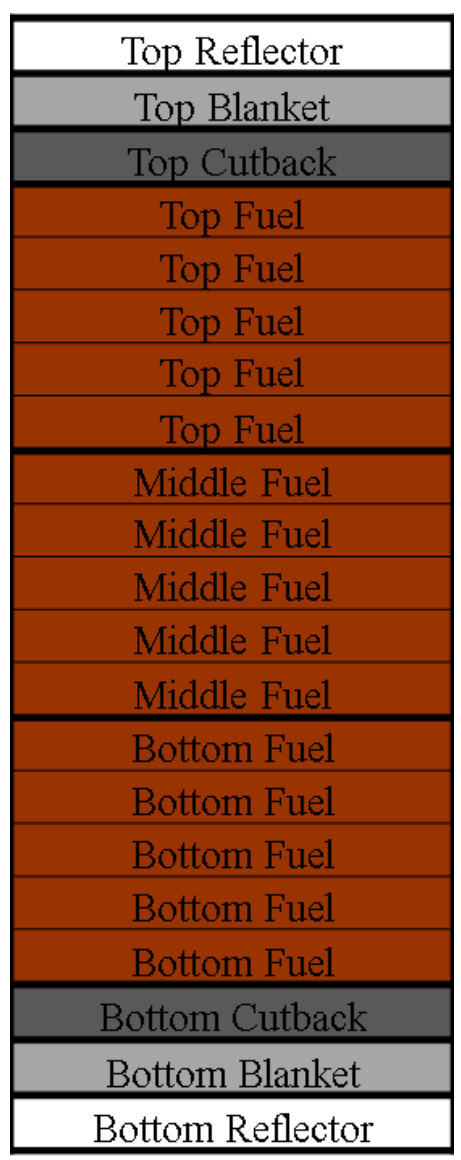

Fig. 2. The axial core configuration of the $\mathrm{I}^{2} \mathrm{~S}$ benchmark problem

Table 1. Height of each axial region (Hon et al., 2016)

\begin{tabular}{|c||c|}
\hline Axial Region & Height $(\mathbf{c m})$ \\
\hline \hline Top, Middle and Bottom Fuel & 20.44192 \\
\hline Top and Bottom Cutback & 15.3416 \\
\hline Top and Bottom Blanket & 15.3416 \\
\hline Top and Bottom Reflector & 30 \\
\hline
\end{tabular}

Each fuel assembly consists of a 19×19 square lattice of pin cells with 336 fuel pins, 24 guide tubes and 1 instrumentation tube in the center. The assembly configuration for 3 Westinghouse Integral Fuel Burnable Absorber (IFBA) loading patterns is illustrated in Fig. 3. Each pin cell is a square, $1.21056 \mathrm{~cm}$ in width, composed of a fuel pin and surrounding moderator. Centered in the pin cell is a circular void region, surrounded by an annular silicide $\mathrm{U}_{3} \mathrm{Si}_{2}$ fuel region, an IFBA coating of $0.00150 \mathrm{~cm}$ (if present) and an advanced stainless steel (APMT) cladding. 


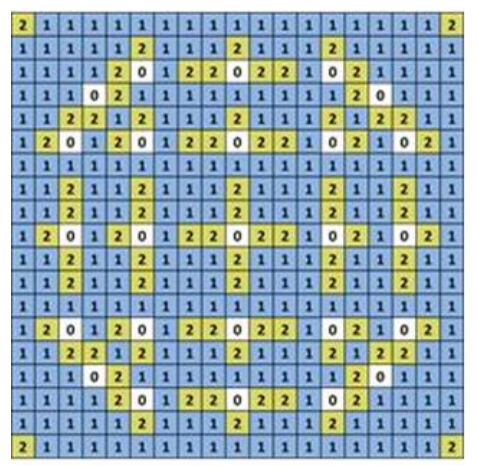

(a) 84 IFBA

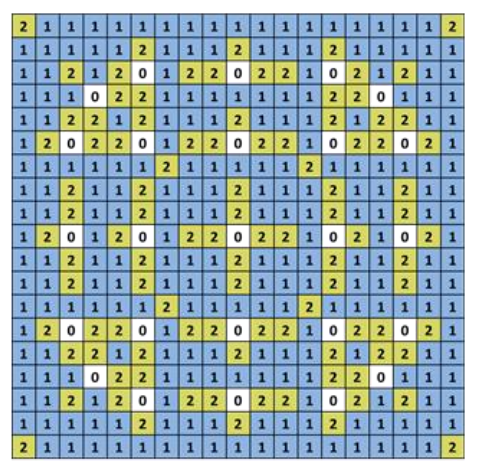

(b) 156 IFBA

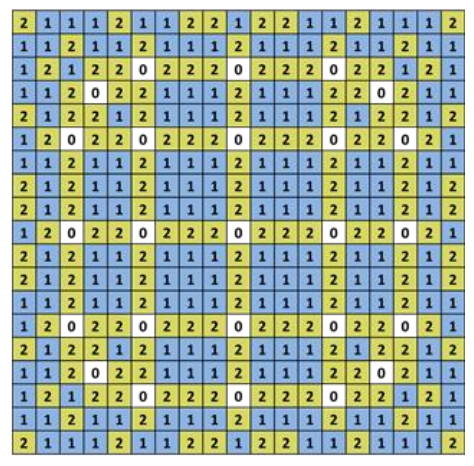

(c) 100 IFBA

Fig. 3. $\mathrm{I}^{2} \mathrm{~S}$ fuel assembly geometry (Hon et al., 2016)

(0: Guide or Instrumentation Tube; 1: Non IFBA Fuel: 2: IFBA Fuel)

There are 54 unique fuel assemblies given the number of uranium enrichments, coolant and fuel temperatures, coolant density and burnup points in the benchmark problem as shown in Table 2. An 8-group cross section library for these assemblies and the reflectors are provided in Hon et al. (2016).

Table 2. Description of the 54 unique assemblies used to define the benchmark problem (Hon et al., 2016)

\begin{tabular}{|c|c|c|c|c|c|c|}
\hline \multirow[b]{2}{*}{ Mesh } & \multicolumn{3}{|c|}{ Thermodynamic properties } & \multicolumn{3}{|c|}{$\begin{array}{c}\text { Burnup (BOC }+10 \text { days) } \\
(\mathrm{MWd} / \mathrm{T})\end{array}$} \\
\hline & $\begin{array}{c}\text { Coolant } \\
\text { Temp. } \\
(\mathrm{K})\end{array}$ & $\begin{array}{l}\text { Coolant } \\
\text { Density } \\
\left(\mathrm{g} / \mathrm{cm}^{3}\right)\end{array}$ & $\begin{array}{c}\text { Fuel } \\
\text { Temp. } \\
(\mathrm{K}) \\
\end{array}$ & $\begin{array}{c}0 \mathrm{x} \\
\text { burned }\end{array}$ & $\begin{array}{c}1 \mathrm{x} \\
\text { burned }\end{array}$ & $\begin{array}{c}2 \mathrm{x} \\
\text { burned }\end{array}$ \\
\hline Blanket Top & 596.9 & 0.665 & 648.0 & 174 & 5932 & 12447 \\
\hline Blanket Bot & 552.8 & 0.765 & 602.0 & 176 & 6281 & 12511 \\
\hline 4.45\% Cutback Top & 596.1 & 0.668 & 703.6 & 341 & 12185 & 24269 \\
\hline 4.45\% Cutback Bot. & 553.9 & 0.763 & 669.0 & 393 & 15026 & 27653 \\
\hline 4.65\% Cutback Top & 596.1 & 0.668 & 703.6 & 351 & 11993 & 25071 \\
\hline 4.65\% Cutback Bot. & 553.9 & 0.763 & 669.0 & 412 & 14519 & 29362 \\
\hline 4.45\%, 84IFBA Top & 589.7 & 0.686 & 748.9 & 486 & 17374 & 34548 \\
\hline 4.45\%, 84IFBA Mid & 576.3 & 0.719 & 754.7 & 522 & 19190 & 36979 \\
\hline 4.45\%, 84IFBA Bot. & 561.8 & 0.749 & 721.6 & 518 & 19314 & 36608 \\
\hline 4.45\%, 156IFBA Top & 589.7 & 0.686 & 748.9 & 523 & 20074 & 36850 \\
\hline 4.45\%, 156IFBA Mid & 576.3 & 0.719 & 754.7 & 562 & 22390 & 39341 \\
\hline 4.45\%, 156IFBA Bot. & 561.8 & 0.749 & 721.6 & 557 & 22726 & 38903 \\
\hline $4.65 \%, 84 \mathrm{IFBA}$ Top & 589.7 & 0.686 & 748.9 & 514 & 17336 & 36769 \\
\hline 4.65\%, 84IFBA Mid & 576.3 & 0.719 & 754.7 & 560 & 19345 & 39928 \\
\hline 4.65\%, 84IFBA Bot. & 561.8 & & 721.6 & 560 & 19592 & 39864 \\
\hline
\end{tabular}


0.749

\begin{tabular}{lllllll}
$4.65 \%, 100 I F B A$ Top & 589.7 & 0.686 & 748.9 & 517 & 19718 & 36439 \\
$4.65 \%, 100 I F B A$ Mid & 576.3 & 0.719 & 754.7 & 547 & 20587 & 38639 \\
$4.65 \%, 100$ IFBA Bot. & 561.8 & 0.749 & 721.6 & 538 & 20041 & 38053 \\
\hline
\end{tabular}

\section{Whole Core Neutronics Analysis}

As mentioned in section 1, whole-core calculations using the Monte Carlo method requires careful analysis for fission source convergence. For this reason, in this section we analyze 50 independent MCNP5 calculations in the benchmark problem in which the core eigenvalue and the radially integrated axial fission density distribution are tallied. The calculations are performed in only $1 / 8^{\text {th }}$ of the core, taking advantage of the radial symmetry. This simplifies the analysis since the core size being small in mean free path in the radial direction isolates the convergence issue to the axial direction. The radial integration further simplifies the analysis since the Monte Carlo computation time is significantly reduced, while maintaining acceptable statistical uncertainty. Additional four independent calculations are performed where the fission density (FD) is tallied in each individual pin in all regions of the reactor. Note that tallying the pin FD distribution in all 50 cases would have been computationally prohibitive.

A COMET calculation in the benchmark problem is also performed to assist the analysis of the Monte Carlo results. Since COMET is several orders of magnitude faster than MCNP, the full core was explicitly modeled to calculate the core eigenvalue and the fuel pin FD distribution in the entire core. The same 8-group cross section library as discussed in the previous section was used in both the whole core MCNP calculations and the computation of the response function library for COMET.

\subsection{MCNP axial fission density}

The MCNP calculation was repeated 50 times with a different random seed number. Calculations for this benchmark problem were performed on a 96-CPU cluster. Each run used 1,000 inactive and 2,000 active cycles with 600,000 particles per cycle to tally the (radiallyintegrated) axial fission density distribution. Because the fission density was not tallied in each individual fuel pin, each calculation took only about 280 CPU hours (i.e. less than 3 hours) on the cluster. We note that the initial fission source distribution for all the 50 independent cases was obtained from a calculation with 6 billion particles $(6,000$ cycles with 1 million particles per cycle). The deviation of the axial fission density distribution (difference) from the average of the 50 cases is shown in Fig. 4. The average itself (hereafter referred to as "AFD") is shown in Fig. 5. This average and its standard deviation are calculated by Equations (4) and (5), respectively.

$$
\overline{A F D}_{i}=\frac{1}{N} \sum_{n=1}^{N} A F D_{i}^{n}
$$




$$
\frac{\delta\left(\overline{A F D}_{i}\right)}{\overline{A F D}_{i}}=\sqrt{\frac{1}{N(N-1)} \sum_{n=1}^{N}\left[\left(A F D_{i}^{n}\right)^{2}-\left(\overline{A F D}_{i}\right)^{2}\right]}
$$

where $\overline{A F D}_{i}$ represents the average (expected) radially-integrated axial fission density in axial region $i, \delta\left(\overline{A F D}_{i}\right)$ is its standard deviation, $A F D_{i}^{n}$ stands for the radially-integrated axial fission density in axial region $i$ for the $n^{\text {th }}$ MCNP5 calculation, and $N$ denotes the total number of MCNP5 calculations.

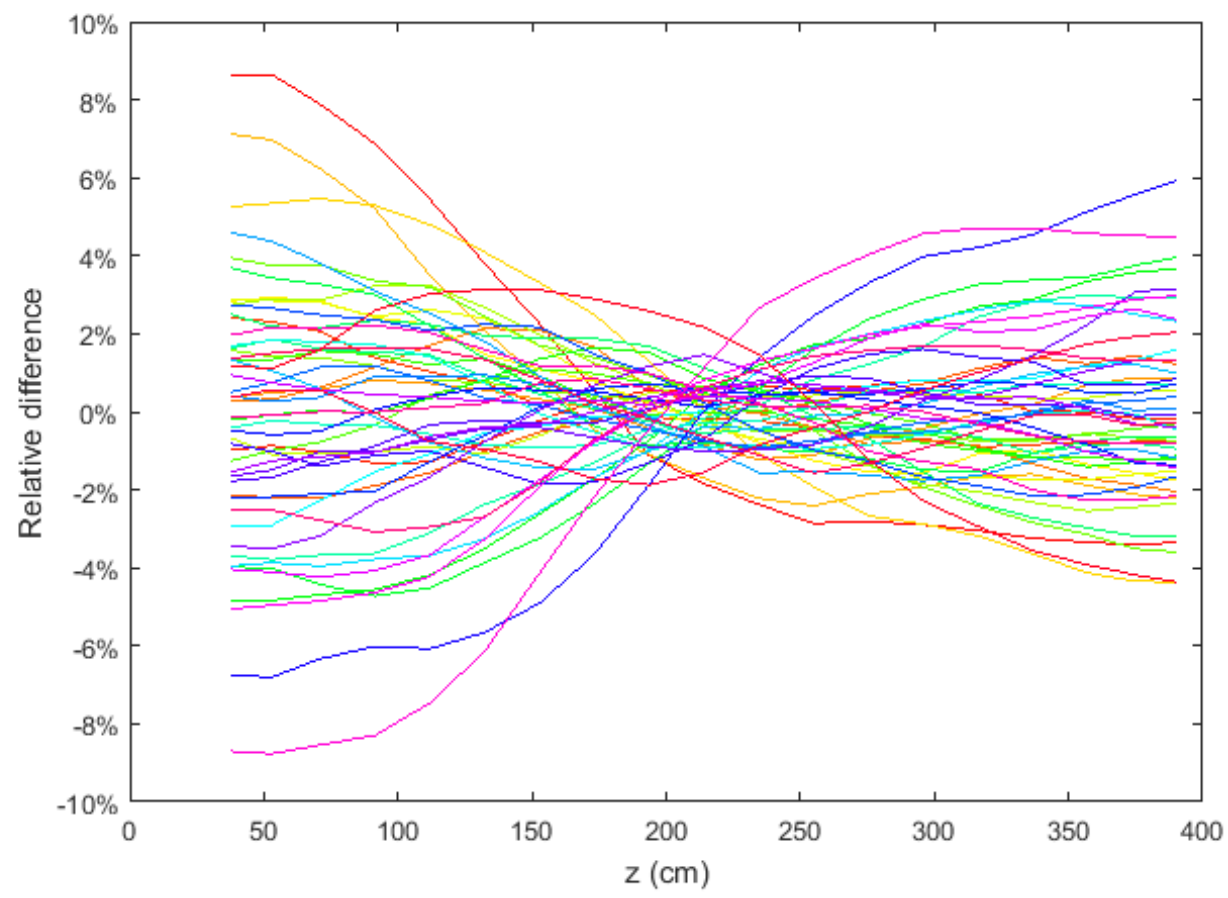

Fig. 4. The deviation of the axial fission density distribution calculated by 50 independent MCNP5 runs from the average

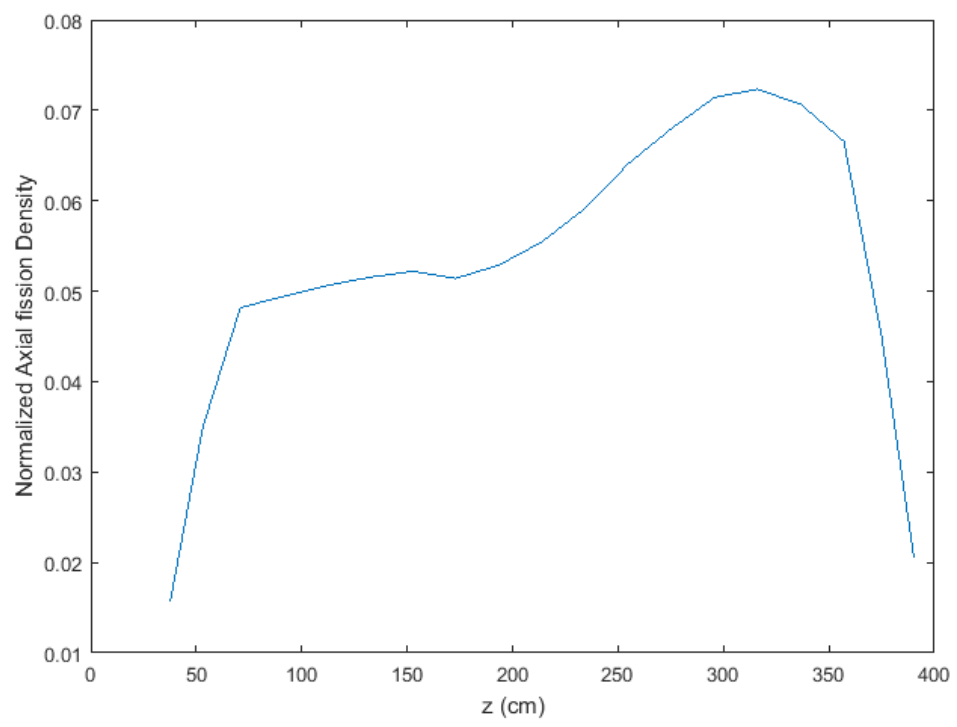


Fig. 5. The average of the axial fission density distributions calculated by 50 independent MCNP5 runs

It can be seen from Fig. 4 that the deviation of the axial fission density distribution predicted by the 50 independent MCNP5 runs from the AFD varies from $-9 \%$ to $+9 \%$, while the uncertainty in the MCNP5 result is in the range of $0.03 \%$ to $0.1 \%$. More importantly, the deviation of each independent MCNP5 run is tilted rather than randomly distributed. As a result, the deviation cannot be explained by the uncertainty in MCNP5 solutions. This clearly indicates that the fission source distribution for each independent run is not converged although they passed the MCNP convergence check. It is important to note that, as shown in the next subsection, further increase in the number of inactive cycles may not guarantee the fission source convergence.

Since the number of independent Monte Carlo calculations in this paper is small (50), a robust transport calculation is in order. We use COMET for this purpose to increase confidence in the Monte Carlo estimated average. The relative difference between the COMET axial fission density distribution and the AFD and its standard deviation are presented in Fig. 6. It can be seen that AFD is in excellent agreement with the COMET result, with a relative difference varying from $-0.18 \%$ to $0.13 \%$, which is less than the statistical standard deviation of the MCNP5 average. Note that the uncertainty in the COMET results is relatively insignificant (see Table 4).

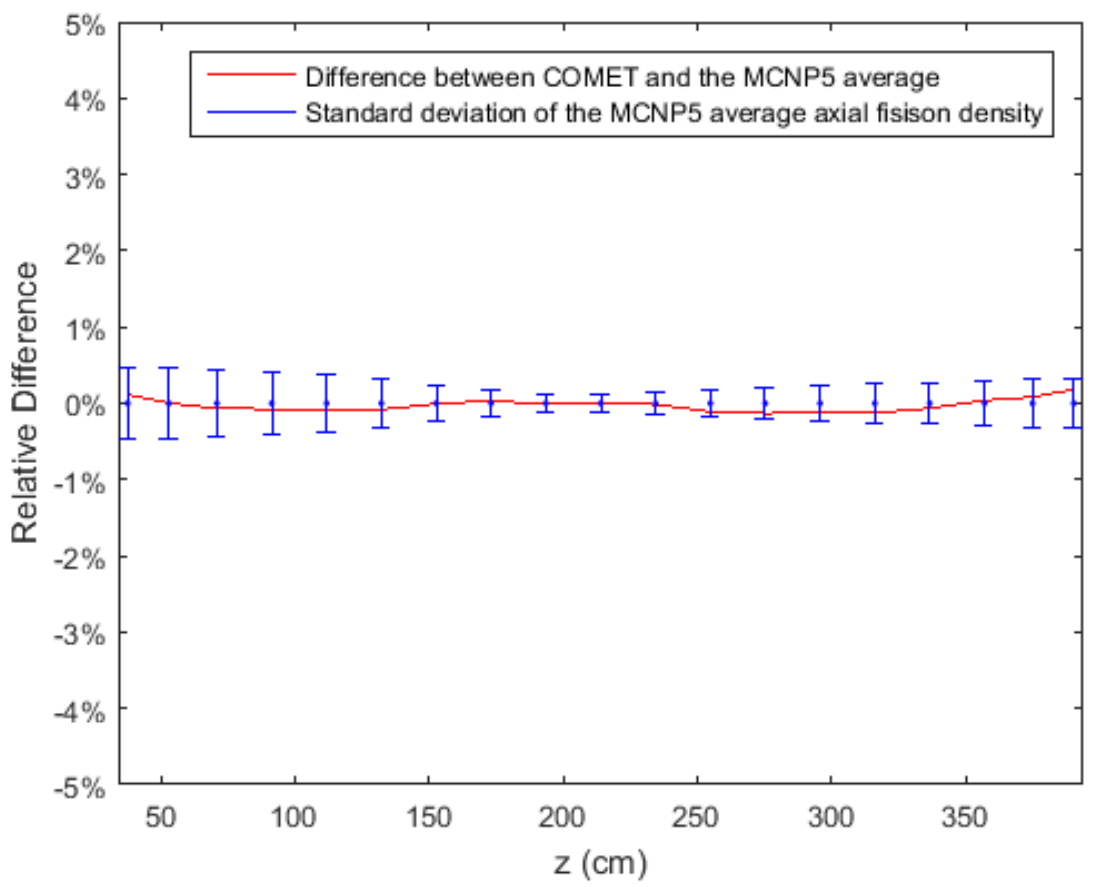

Fig. 6. The deviation of the axial fission density distribution predicted by COMET from the AFD

It must be noted that a single Monte Carlo calculation with a total number of particles (60 billion) equivalent to the total of that of the independent runs does not guarantee source convergence. This was verified in (Zhang, Rahnema, 2016). In this study, the average of 
solutions of many independent runs and the solution of an equivalent single run were compared to an analytic solution. It was found that the deviation of the single run result from the analytic solution was more than 3 times larger than that of the average.

\subsection{MCNP calculations to tally pin fission density distribution}

Ideally, one should also perform at least $50 \mathrm{MCNP}$ independent runs and use their average as to compute the final pin fission density distribution in the core. However, MCNP5 calculations become computationally very expensive when the fission density distribution in all the fuel pins in the core is tallied. Given our limited computer resources, only four additional independent calculations were performed to tally pin fission density. The number of inactive and active cycles and the particle number per cycle as well as the results for each MCNP5 calculations are illustrated in Table 3. The initial fission source phase space distribution for MCNP5 run 1 was obtained from that of the 6 billion particle case mentioned earlier. For the other runs, the initial phase space distribution was taken from the immediate previous calculation. In other words, the total number of particles including the skipped cycle (see Table 3) used for source convergence for runs 1-4 were $7,13,19$, and 26 billion, respectively.

Table 3. Numbers of Particle Histories and Results for Each MCNP Run

\begin{tabular}{|c|c|c|c|c|c|}
\hline & & $\begin{array}{c}\text { MCNP5 } \\
\text { run1 } \\
\end{array}$ & $\begin{array}{c}\text { MCNP5 } \\
\text { run2 } \\
\end{array}$ & $\begin{array}{c}\text { MCNP5 } \\
\text { run3 } \\
\end{array}$ & $\begin{array}{c}\text { MCNP5 } \\
\text { run4 } \\
\end{array}$ \\
\hline \multirow{3}{*}{ Inactive cycles } & \# of cycles & 1,000 & 1,000 & 1,000 & 1,000 \\
\hline & \# of particles per cycle & 1E6 & 1E6 & 1E6 & 2E6 \\
\hline & Total \# of particles & $1 \mathrm{E9}$ & $1 \mathrm{E9}$ & $1 \mathrm{E9}$ & 2E9 \\
\hline \multirow{3}{*}{ Active cycles } & \# of cycles & 5,000 & 5,000 & 5,000 & 4,000 \\
\hline & \# of particles per cycle & $1 \mathrm{E} 6$ & $1 \mathrm{E} 6$ & $1 \mathrm{E} 6$ & 2E6 \\
\hline & Total \# of particles & $5 \mathrm{E} 9$ & $5 \mathrm{E} 9$ & $5 \mathrm{E} 9$ & $8 \mathrm{E} 9$ \\
\hline \multicolumn{2}{|c|}{ CPU times* (hours) } & 15,148 & 15,274 & 15,293 & 18,390 \\
\hline \multicolumn{2}{|c|}{ Eigenvalue } & 1.01604 & 1.01603 & 1.01603 & 1.01604 \\
\hline \multicolumn{2}{|c|}{ Eigenvalue uncertainty (pcm) } & 1 & 1 & 1 & 1 \\
\hline \multicolumn{2}{|c|}{ Average pin fission uncertainty (\%) } & 0.30 & 0.30 & 0.30 & 0.26 \\
\hline \multicolumn{2}{|c|}{ Maximum pin fission uncertainty (\%) } & 1.95 & 1.94 & 1.94 & 1.71 \\
\hline
\end{tabular}

*The source convergence times were not included.

The MCNP5 calculations took about 15,200 to 18,390 CPU hours as shown in Table 3 or equivalently about 150 to 210 hours on the 96-CPU cluster. It should be noted the 400 to 3,200 CPU hours for source convergence were not included in Table 3. The core eigenvalues for these runs are within 1 standard deviation $(1 \mathrm{pcm})$ of the statistical uncertainty of the calculations. The average and maximum uncertainty of the MCNP pin fission density distribution is $0.30 \%$ and $1.94 \%$, respectively. The largest uncertainty occurs in the peripheral regions in the top blanket, where the neutron flux is relatively low.

To examine the convergence of the MCNP solutions 1-4, the deviations of radially-integrated axial fission distribution of the runs 1-4 and COMET from the AFD (see Fig. 5) are illustrated in 
Fig. 7. The corresponding uncertainties in the MCNP and COMET calculations are shown in Table 4.

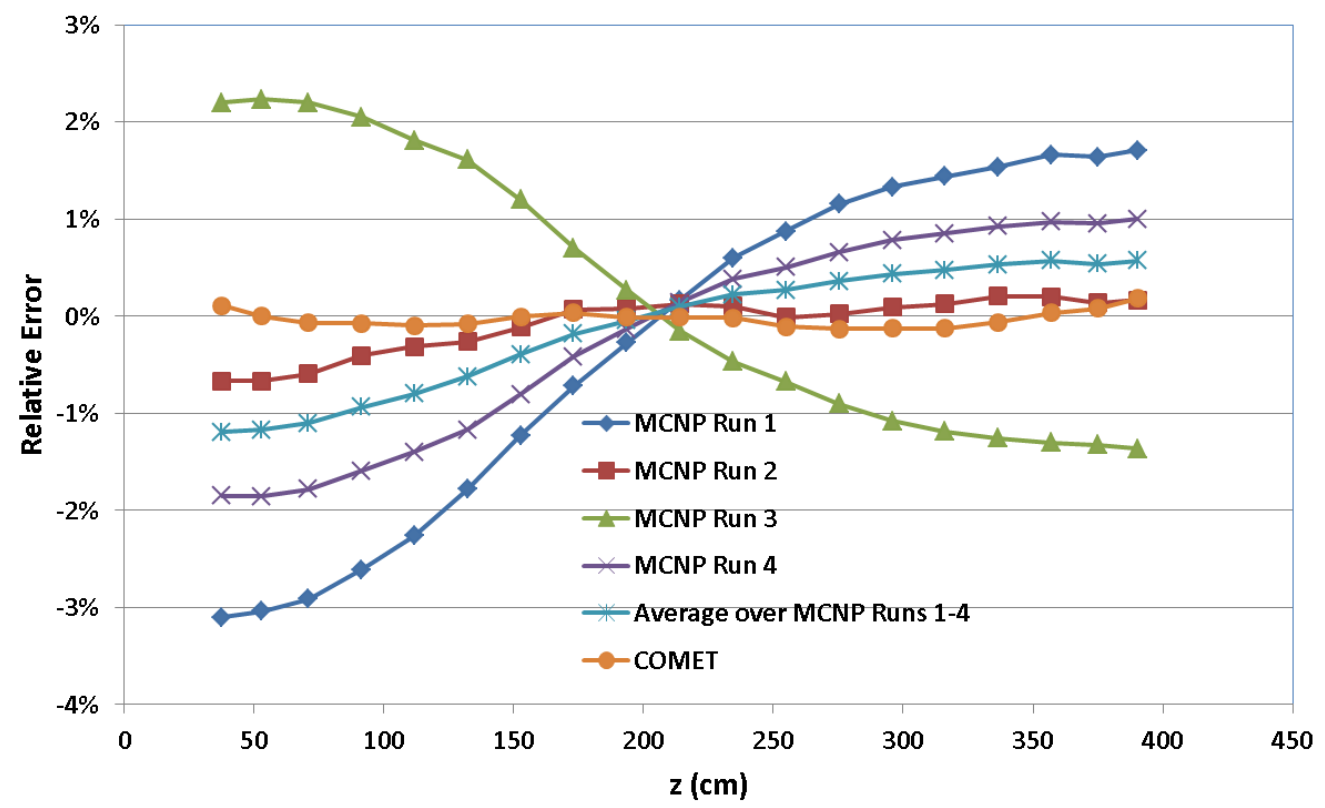

Fig. 7. The deviation of the radially-integrated axial fission density distribution predicted by MCNP5 and COMET from the AFD

Table 4. Uncertainty in the radially-integrated axial fission density distribution

\begin{tabular}{|c||c||}
\hline & Uncertainty \\
\hline \hline MCNP5 run 1 & $0.006 \%$ \\
\hline MCNP5 run 2 & $0.006 \%$ \\
\hline MCNP5 run 3 & $0.006 \%$ \\
\hline MCNP5 run 4 & $0.004 \%$ \\
\hline Average over MCNP5 runs 1-4 & $0.002 \%$ \\
\hline COMET & $0.003 \%$ \\
\hline
\end{tabular}

It can be seen from Fig. 7 that the discrepancy among the axial fission density distributions predicted by MCNP5 runs 1-4 is very large, about 2-3 orders of magnitude higher than the MCNP5 reported uncertainty. The results of run 2 agree very well with the AFD (i.e., within 2 standard deviations of the AFD uncertainty), while, the deviation of runs 1,3 , and 4 as well as the average results of runs $1-4$ from the AFD varies within $-3.2 \%$ to $+2.1 \%$. This clearly indicates that the axial fission source distributions in runs 1, 3, and 4 are still not converged despite using $7-26$ billion particles for source convergence. Therefore, it can be concluded that the averaged solution using a limited number of independent calculations (runs 1-4) is not statistically reliable. The solution from run 2 happened to agree with the converged solution obtained by averaging the results of the 50 independent runs as well as that of COMET. As a result, only the pin fission density distribution from run 2 was compared with that predicted by COMET. 
The following statistical quantities were used to check the agreement/disagreement between COMET and MCNP5 pin fission densities: the average (AVE), root mean square (RMS), mean flux weighted (MRE), and maximum (MAX) relative difference. These statistical quantities are mathematically defined by equations (6)-(9).

$$
\begin{gathered}
A V E=\frac{1}{N} \sum_{i=1}^{N} e_{i} \\
R M S=\sqrt{\frac{1}{N} \sum_{i=1}^{N} e_{i}^{2}} \\
M R E=\frac{\sum_{i=1}^{N} F D_{i} e_{i}}{\sum_{i=1}^{N} F D_{i}} \\
M A X=\max \left\{e_{i} \mid i=1, \ldots, N\right\}
\end{gathered}
$$

where $N$ is the total number of fuel pins in the problem, $F D_{i}$ is the pin fission density in fuel pin $i$, and $e_{i}$ represents the relative difference between the MCNP and COMET pin fission density.

Table 5. Comparison of fuel pin fission density distributions and the eigenvalues predicted by MCNP5 and COMET

\begin{tabular}{|c||c|c|c|c|c|}
\hline Quantities & AVG (\%) & RMS (\%) & MRE (\%) & MAX (\%) & $\Delta k(\mathrm{pcm})$ \\
\hline MCNP run2 & 0.41 & 0.54 & 0.35 & 5.49 & 19 \\
\hline $\begin{array}{c}\text { Average over } \\
\text { MCNP runs 1-4 }\end{array}$ & 1.08 & 1.29 & 0.94 & 5.48 & 19 \\
\hline
\end{tabular}

Table 6. Uncertainty of the pin fission density distribution predicted by MCNP5 and COMET

\begin{tabular}{|c|c|c|}
\hline Uncertainty & Average (\%) & Maximum (\%) \\
\hline \hline MCNP run2 & 0.30 & 1.94 \\
\hline Average over MCNP runs 1-4 & 0.14 & 0.92 \\
\hline COMET & 0.12 & 0.56 \\
\hline
\end{tabular}

The comparison of the fission densities predicted by COMET and MCNP run 2 as well as the average results of MCNP runs 1-4 is presented in Table 5. The uncertainty of the MCNP and COMET pin fission densities is shown in Table 6. As expected, it is found that the pin fission 
density distribution from MCNP run 2 agrees very well with that computed by COMET (i.e., within 3 standard MCNP uncertainties) while the difference between the averaged MCNP pin fission density results (runs 1-4) and those of COMET is significantly beyond the combined MCNP and COMET statistical uncertainty. This indicates that the difference between the pin fission density computed by COMET and the MCNP runs 1-4 average is actually dominated by the MCNP axial fission source oscillations (i.e., non-convergence).

It should be pointed out that the MCNP5 convergence of the fission source distribution in the radial direction is not an issue for this particular benchmark problem since only $1 / 8^{\text {th }}$ of the core in the radial direction was modeled by MCNP5 in this work. However, if MCNP5 calculations are extended to full-core benchmark problems, one needs to not only increase the number of particles per cycle by eight times to maintain the same uncertainty, but also significantly increase the number of independent MCNP5 runs to achieve fission source convergence in the radial direction.

\section{Summary and Conclusions}

In this paper, a stylized $I^{2} S-L W R$ benchmark problem was used to study the fission source convergence in Monte Carlo calculations. This was done by comparing the axial fission density distributions estimated by 50 independent MCNP calculations with their averaged result as well as with the COMET solution. It was found that the deviation of the axial fission density distribution predicted by each independent MCNP run from the average of the 50 runs is two orders of magnitude higher than the Monte Carlo report statistical uncertainty. Further, the slope and the magnitude of the deviation were found to be random as expected. This confirms the conclusion that a large number of independent runs are necessary to obtain a converged solution to a large eigenvalue problem. This conclusion was also found to be true when a finer detailed solution (i.e., fission density in individual fuel pins) is sought. In particular, averaging solutions (individual pin fission density) from only a few cases (4) is not sufficient to achieve a converged solution.

In this study it was shown that the COMET results agree very well with those obtained by averaging the results from the 50 independent Monte Carlo cases. That is, the agreement is within one standard deviation of the averaged results from the 50 Monte Carlo calculations. Therefore, COMET can serve as an excellent method for seeking detailed solutions to wholecore (large eigenvalue) problems since achieving converged Monte Carlo solutions in such cases is generally computationally prohibitive. Because of this, the fuel pin fission density distribution generated by COMET can be taken as the reference solution in the $\mathrm{I}^{2} \mathrm{~S}$-LWR benchmark problem. It must be noted that the number of independent Monte Carlo calculations cannot be determined a priori as it depends on the desired magnitude of the aforementioned standard deviation of the averaged results.

In this paper, the study of the Monte Carlo solution convergence was limited to the $I^{2} S-L W R$ benchmark problem. It would be interesting to extend this study to a broader class of benchmark problems typical of PWRs, BWRs, CANDU, and Gas Cooled thermal systems which vary in size measured by neutron MFP. 


\section{Acknowledgements}

This work was supported by NEUP Award Number DE-AC07-O5ID14517. Any opinions, findings, conclusions, or recommendations expressed in this publication are those of the authors and do not necessarily reflect the views of the Department of Energy Office of Nuclear Energy. The Second Author own equity in a company that has licensed the COMET technologies from Georgia Tech. This study which is a demonstration of COMET could affect his personal financial status. The term of this arrangement have been reviewed and approved by Georgia Tech in accordance with its conflict of interest policies.

\section{References}

Connolly, K.J., Rahnema, F., 2013. A Heterogeneous Coarse Mesh Transport Method for Neutronic Analysis of Prismatic Reactors. Annual Nuclear Energy, 56, 87.

Hon, R., Kooreman, G., Rahnema, F., Petrovic, B., 2016. Stylized Whole-Core Benchmark of the Integral Inherently Safe Light Water Reactor (I ${ }^{2}$ S-LWR) Concept. Annals of Nuclear Energy, (submitted).

Rahnema, F., Zhang, D., Connolly, K.J., 2014. The COMET method Reactor Physics Calculations. 19th Pacific Basin Nuclear Conference, Vancouver, Canada, August 24-28.

Ulmer, R.M., Rahnema, F., Connolly, K.J., 2016. A Neutronic Benchmark Specification and COMET Solution for the Advanced Burner Test Reactor. Annals of Nuclear Energy, 87, 76106.

Ueki, T., Brown, F. B., 2005. Stationarity Modeling and Informatics-Based Diagnostics in Monte Carlo Criticality Calculations. Nuclear Science and Engineering, 149, 38-50.

X-5 Monte Carlo Team, 2005. MCNP-A General Monte Carlo N-Particle Transport Code, Version 5. Los Alamos National Laboratory.

Rahnema, F., Zhang, D., Connolly, K.J., 2014, The COMET method Reactor Physics Calculations. 19th Pacific Basin Nuclear Conference, Vancouver, Canada, August 24-28.

Mosher, S., Rahnema, F., 2006. The Incident Flux Response Expansion Method for Heterogeneous Coarse Mesh Transport Problems. Transport Theory and Statistical Physics, 34, 1-26.

Zhang, D., Rahnema, F., 2012a. An Efficient Hybrid Stochastic/Deterministic Coarse Mesh Neutron Transport Method. Annals of Nuclear Energy, 41, pp. 1-11.

Zhang, D. Rahnema, F., 2012b. COMET Solutions to a Stylized BWR Benchmark Problem. PHYSOR 2012 - Advances in Reactor Physics - Linking Research, Industry, and Education, Knoxville, Tennessee, USA, April 15-20.

Zhang, D., Rahnema, F., 2012c. COMET Whole-Core Solutions to a 3-Dimensional PWR Benchmark Problem with Gadolinium. PHYSOR 2012 - Advances in Reactor Physics Linking Research, Industry, and Education, Knoxville, Tennessee, USA, April 15-20.

Zhang, D., Rahnema, F., 2016a. An Implicit Correlation Method for COMET Core Eigenvalue Uncertainty Analysis. Nuclear Science and Engineering, (accepted).

Zhang, D., Rahnema, F., 2016b. Analysis of Monte Carlo Solutions to Stylized PWR Benchmark Problems. 2016 International Congress on Advances in Nuclear Power Plants (ICAPP 2016), San Francisco, CA, USA, April 17-20. 


\section{Appendix A: Description of COMET Calculations}

The COMET calculation used in this paper is described in this appendix. Theoretically, any sub-volume in the core can be chosen as a coarse mesh. However, in order to minimize the number of unique coarse meshes which can sufficiently represent the whole core configuration it is natural to choose the unique coarse meshes to be of assembly size. As a result, 59 unique coarse meshes were used to model the $\mathrm{I}^{2} \mathrm{~S}$ core by COMET. This included 54 unique fuel coarse meshes with the four different burnup points and three IFBA loading patterns and five reflector blocks with different dimensions at different locations. The material properties and dimension of these unique lattices are listed in Table A.1.

Table A.1. Dimension and material properties of unique coarse meshes (lattice cells)

\begin{tabular}{|c|c|c|c|}
\hline index & $\begin{array}{c}\text { Coarse } \\
\text { Mesh Type }\end{array}$ & Material Property & Dimension (cm) \\
\hline 1 & Fuel & Blanket Top 0x burned & $23.1013 \times 23.1013 \times 15.3416$ \\
\hline 2 & Fuel & Blanket Bot 0x burned & $23.1013 \times 23.1013 \times 15.3416$ \\
\hline 3 & Fuel & 4.45\% Cutback Top 0x burned & $23.1013 \times 23.1013 \times 15.3416$ \\
\hline 4 & Fuel & 4.45\% Cutback Bot. 0x burned & $23.1013 \times 23.1013 \times 15.3416$ \\
\hline 5 & Fuel & 4.65\% Cutback Top 0x burned & $23.1013 \times 23.1013 \times 15.3416$ \\
\hline 6 & Fuel & 4.65\% Cutback Bot. 0x burned & $23.1013 \times 23.1013 \times 15.3416$ \\
\hline 7 & Fuel & 4.45\%, 84IFBA Top 0x burned & $23.1013 \times 23.1013 \times 20.44192$ \\
\hline 8 & Fuel & 4.45\%, 84IFBA Mid 0x burned & $23.1013 \times 23.1013 \times 20.44192$ \\
\hline 9 & Fuel & 4.45\%, 84IFBA Bot. 0x burned & $23.1013 \times 23.1013 \times 20.44192$ \\
\hline 10 & Fuel & 4.45\%, 156IFBA Top 0x burned & $23.1013 \times 23.1013 \times 20.44192$ \\
\hline 11 & Fuel & 4.45\%, 156IFBA Mid 0x burned & $23.1013 \times 23.1013 \times 20.44192$ \\
\hline 12 & Fuel & $4.45 \%$, 156IFBA Bot. 0x burned & $23.1013 \times 23.1013 \times 20.44192$ \\
\hline 13 & Fuel & $4.65 \%, 84$ IFBA Top 0x burned & $23.1013 \times 23.1013 \times 20.44192$ \\
\hline 14 & Fuel & 4.65\%, 84IFBA Mid 0x burned & $23.1013 \times 23.1013 \times 20.44192$ \\
\hline 15 & Fuel & 4.65\%, 84IFBA Bot. 0x burned & $23.1013 \times 23.1013 \times 20.44192$ \\
\hline 16 & Fuel & 4.65\%, 100IFBA Top 0x burned & $23.1013 \times 23.1013 \times 20.44192$ \\
\hline 17 & Fuel & 4.65\%, 100IFBA Mid 0x burned & $23.1013 \times 23.1013 \times 20.44192$ \\
\hline 18 & Fuel & $4.65 \%, 100$ IFBA Bot. 0x burned & $23.1013 \times 23.1013 \times 20.44192$ \\
\hline 19 & Fuel & Blanket Top 1x burned & $23.1013 \times 23.1013 \times 15.3416$ \\
\hline 20 & Fuel & Blanket Bot $1 \mathrm{x}$ burned & $23.1013 \times 23.1013 \times 15.3416$ \\
\hline 21 & Fuel & 4.45\% Cutback Top 1x burned & $23.1013 \times 23.1013 \times 15.3416$ \\
\hline 22 & Fuel & 4.45\% Cutback Bot. 1x burned & $23.1013 \times 23.1013 \times 15.3416$ \\
\hline 23 & Fuel & 4.65\% Cutback Top 1x burned & $23.1013 \times 23.1013 \times 15.3416$ \\
\hline 24 & Fuel & 4.65\% Cutback Bot. $1 \mathrm{x}$ burned & $23.1013 \times 23.1013 \times 15.3416$ \\
\hline 25 & Fuel & $4.45 \%, 84$ IFBA Top $1 \mathrm{x}$ burned & $23.1013 \times 23.1013 \times 20.44192$ \\
\hline 26 & Fuel & 4.45\%, 84IFBA Mid 1x burned & $23.1013 \times 23.1013 \times 20.44192$ \\
\hline 27 & Fuel & 4.45\%, 84IFBA Bot. 1x burned & $23.1013 \times 23.1013 \times 20.44192$ \\
\hline 28 & Fuel & $4.45 \%, 156 \mathrm{IFBA}$ Top $1 \mathrm{x}$ burned & $23.1013 \times 23.1013 \times 20.44192$ \\
\hline 29 & Fuel & 4.45\%, 156IFBA Mid 1x burned & $23.1013 \times 23.1013 \times 20.44192$ \\
\hline 30 & Fuel & $4.45 \%, 156$ IFBA Bot. $1 x$ burned & $23.1013 \times 23.1013 \times 20.44192$ \\
\hline
\end{tabular}




\begin{tabular}{|c|c|c|c|}
\hline 31 & Fuel & $4.65 \%, 84$ IFBA Top $1 \mathrm{x}$ burned & $23.1013 \times 23.1013 \times 20.44192$ \\
\hline 32 & Fuel & 4.65\%, 84IFBA Mid 1x burned & $23.1013 \times 23.1013 \times 20.44192$ \\
\hline 33 & Fuel & 4.65\%, 84IFBA Bot. 1x burned & $23.1013 \times 23.1013 \times 20.44192$ \\
\hline 34 & Fuel & $4.65 \%, 100 \mathrm{IFBA}$ Top $1 \mathrm{x}$ burned & $23.1013 \times 23.1013 \times 20.44192$ \\
\hline 35 & Fuel & $4.65 \%, 100 I F B A$ Mid 1x burned & $23.1013 \times 23.1013 \times 20.44192$ \\
\hline 36 & Fuel & $4.65 \%, 100$ IFBA Bot. 1x burned & $23.1013 \times 23.1013 \times 20.44192$ \\
\hline 37 & Fuel & Blanket Top 2x burned & $23.1013 \times 23.1013 \times 15.3416$ \\
\hline 38 & Fuel & Blanket Bot $2 \mathrm{x}$ burned & $23.1013 \times 23.1013 \times 15.3416$ \\
\hline 39 & Fuel & $4.45 \%$ Cutback Top 2x burned & $23.1013 \times 23.1013 \times 15.3416$ \\
\hline 40 & Fuel & $4.45 \%$ Cutback Bot. $2 \mathrm{x}$ burned & $23.1013 \times 23.1013 \times 15.3416$ \\
\hline 41 & Fuel & 4.65\% Cutback Top 2x burned & $23.1013 \times 23.1013 \times 15.3416$ \\
\hline 42 & Fuel & 4.65\% Cutback Bot. $2 \mathrm{x}$ burned & $23.1013 \times 23.1013 \times 15.3416$ \\
\hline 43 & Fuel & 4.45\%, 84IFBA Top 2x burned & $23.1013 \times 23.1013 \times 20.44192$ \\
\hline 44 & Fuel & 4.45\%, 84IFBA Mid 2x burned & $23.1013 \times 23.1013 \times 20.44192$ \\
\hline 45 & Fuel & 4.45\%, 84IFBA Bot. $2 \mathrm{x}$ burned & $23.1013 \times 23.1013 \times 20.44192$ \\
\hline 46 & Fuel & $4.45 \%, 156 \mathrm{IFBA}$ Top 2x burned & $23.1013 \times 23.1013 \times 20.44192$ \\
\hline 47 & Fuel & $4.45 \%, 156$ IFBA Mid 2x burned & $23.1013 \times 23.1013 \times 20.44192$ \\
\hline 48 & Fuel & 4.45\%, 156IFBA Bot. 2x burned & $23.1013 \times 23.1013 \times 20.44192$ \\
\hline 49 & Fuel & 4.65\%, 84IFBA Top 2x burned & $23.1013 \times 23.1013 \times 20.44192$ \\
\hline 50 & Fuel & 4.65\%, 84IFBA Mid 2x burned & $23.1013 \times 23.1013 \times 20.44192$ \\
\hline 51 & Fuel & 4.65\%, 84IFBA Bot. 2x burned & $23.1013 \times 23.1013 \times 20.44192$ \\
\hline 52 & Fuel & $4.65 \%, 100 \mathrm{IFBA}$ Top 2x burned & $23.1013 \times 23.1013 \times 20.44192$ \\
\hline 53 & Fuel & $4.65 \%, 100 I F B A$ Mid 2x burned & $23.1013 \times 23.1013 \times 20.44192$ \\
\hline 54 & Fuel & $4.65 \%, 100$ IFBA Bot. $2 x$ burned & $23.1013 \times 23.1013 \times 20.44192$ \\
\hline 55 & Reflector & Mixture of $70 \mathrm{wt} \%$ SS \& 30wt $\% \mathrm{H} 2 \mathrm{O}$ & $23.1013 \times 23.1013 \times 15.3416$ \\
\hline 56 & Reflector & Mixture of $70 \mathrm{wt} \%$ SS \& 30wt $\% \mathrm{H} 2 \mathrm{O}$ & $23.1013 \times 23.1013 \times 20.44192$ \\
\hline 57 & Reflector & Mixture of $70 \mathrm{wt} \% \mathrm{SS} \& 30 \mathrm{wt} \% \mathrm{H} 2 \mathrm{O}$ & $23.1013 \times 23.1013 \times 15.3416$ \\
\hline 58 & Reflector & Mixture of $70 \mathrm{wt} \% \mathrm{SS} \& 30 \mathrm{wt} \% \mathrm{H} 2 \mathrm{O}$ & $23.1013 \times 23.1013 \times 20.44192$ \\
\hline 59 & Reflector & Mixture of $70 \mathrm{wt} \%$ SS \& 30wt $\% \mathrm{H} 2 \mathrm{O}$ & $23.1013 \times 23.1013 \times 20.44192$ \\
\hline
\end{tabular}

The response coefficients for each unique coarse mesh were generated by the stochastic response function generator and then compiled into a response function library for COMET whole-core calculations. The expansion orders used in the response function calculations were 4, 4,2 and 2 in the two spatial variables ( $\mathrm{x}$ and $\mathrm{y}$ on coarse mesh surfaces) and two angular variables, respectively. For the convenience, the expansion order is denoted as $\{4,4,2,2\}$ thereafter. For each local fixed-source problem defined in Equations (2) and (3), 30 million particle histories were followed to compute response functions, and it took about 2.1 hours for a fuel coarse mesh and 1 hour for a reflector coarse mesh on a single CPU. Those response coefficients must be generated for each unique coarse mesh and each energy group. The total response function generation time was 2,720 hours on a single CPU, or equivalently about 28 hours in the 96-CPU cluster. The response function library was then used in COMET at an expansion order $\{4,4,2,2\}$ to perform whole core transport calculations for the $\mathrm{I}^{2} \mathrm{~S}$ benchmark problem. The eigenvalue and CPU time for the COMET full core calculation is shown in Table A.2. 
Table A.2. Comparison of the core eigenvalue and CPU times

\begin{tabular}{|c|c|c|}
\hline \hline Eigenvalue & Uncertainty (pcm) & CPU Time (hours) \\
\hline \hline 1.01622 & 1 & 12.2 \\
\hline \hline
\end{tabular}

